\title{
TEMPO TRANSVERSAL
}

\section{TRANSVERSAL TIME}

\section{Resumo}

Temáticas feministas e de gênero ganharam proeminência em publicações nos Estados Unidos no início dos anos 90. A tradução para o português, em 2006, da coletânea organizada por Kate Nesbitt, em 1995, viabilizou amplo acesso nacional aos debates teóricos dos centros especializados do Norte. Este artigo apresenta uma revisão bibliográfica de alguns destes textos e sugere potencialidades e limites para a historiografia da arquitetura e da cidade. A análise dos textos leva a uma concepção transversal da narrativa histórica a partir do olhar de diferentes sujeitos e dos atravessamentos do tempo cotidiano com o tempo histórico, do espaço sensível com o espaço construído.

Palavras-chave: Corpo, Gênero, Arquitetura

\section{Abstract}

Feminist and gender issues have gained prominence in the United States in the early '90s. When the collection edited by Kate Nesbitt in 1995 was translated to Portuguese in 2006, it enabled broad access to the debates from specialized centers in the north. The text presents a literature review of these, suggests the potential, and limits to the historiography of architecture and the city. The analysis of the texts leads to a transverse view of historical narrative through the eyes of different subjects, which reflect the crossings of everyday time with abstract time, sensitive space with built space.

Key-words: Boby, Gender, Architecture

\section{Disjunções}

Ainda que o movimento moderno tenha sido alvo de crítica na pós-modernidade, Bernard Tschumi apontou o fato de que a satisfação do desejo humano pela arquitetura continuava sendo considerada uma atitude decadente da disciplina. Persistia um certo julgamento moral em relação ao prazer em favor de valores elevados do espírito. $\mathrm{Na}$ modernidade, a satisfação que o espaço arquitetônico poderia desencadear foi constantemente uma justificativa menor, irrelevante ou de mau gosto diante de responsabilidades morais, técnicas ou funcionais do projeto (TSCHUMI, 2006d, p. 575) e consequentemente um critério menos pertinente para a compreensão e estabelecimento de sua relevância.

Vanguardas europeias racionalistas, funcionalistas e puristas atribuíram valor positivo à ordem, à ortogonalidade, à homogeneidade ao mesmo tempo em que apontavam e condenavam excessos ornamentais, variações formais e contradições. A arquitetura do movimento moderno 
consolidou semelhanças na medida em que suprimiu uma multiplicação de dissidências. A história da arquitetura moderna se estabeleceu negando o que não lhe servia como imagem da razão e se aproximou mais de certas correntes artísticas do que de outras - purismos ao invés do surrealismo e dadaísmo, por exemplo. Isso voltaria a acontecer nas revoltas pós-64, quando a expectativa de revolução social na arquitetura moderna se revela instrumento de controle social autoritário com desdobramentos semelhantes. Bernard Tschumi (1996) relata na introdução do livro Architecture and Disjunction as frustrações políticas em relação à arquitetura naquele momento. O contexto o teria motivado a desenvolver os artigos e seus "Anúncios de Arquitetura", escritos entre os anos 70 e 80 e reunidos no livro. Na publicação recente do manuscrito de Henri Lefebvre, Toward and Architecture of Enjoyment, o editor e arquiteto Łukasz Stanek menciona em sua introdução os aspectos do debate francês nas áreas da sociologia e da filosofia, com os quais Tschumi teve contato durante a década de 1960.

Para o arquiteto, os embates se dão em torno de antagonismos "que na maioria das vezes são complementares: Ordem e desordem, estrutura e caos, ornamento e pureza, racionalidade e sensualidade." (TSCHUMI, 2006a, p. 575) A crítica assimila e reproduz essa lógica dialética ao opor estilos e correntes de pensamento em função destas categorias. Os antagonismos delineiam a crítica, a teoria e a historiografia, ao mesmo tempo em que estas representações atribuem valores aos projetos.

Tschumi distingue duas maneiras de apreensão do espaço arquitetônico. A primeira o compreende como uma totalidade material mensurável, disposição de volumes, cheios e vazios, tradução abstrata e mental que sintetiza no termo Pirâmide. A outra compreende o espaço como uma experiência sensível, percebido a partir da sucessão de fragmentos táteis que se revelam no percurso, com dispositivo de afeto e memória, e que se resume no termo Labirinto.

Ambas as dimensões, Pirâmide e Labirinto, constituem o espaço, mas o autor reconhece uma assimetria entre elas. Os modos de representação tradicionais na arquitetura privilegiam a tradução do espaço como Pirâmide em vez de descrevê-lo enquanto Labirinto.

O próprio sistema de representação seria produto dos pressupostos da lógica racional. O título do artigo de Bernard Tschumi, O prazer da Arquitetura, faz alusão ao livro de Roland Barthes, O prazer do texto. Os argumentos clássicos seriam, no entendimento do arquiteto, incompatíveis com "a natureza paradoxal" da temática do prazer. Parafraseando o próprio Barthes "O prazer não se rende facilmente a análise." (TSCHUMI, 2006d, p. 576 )

O autor recorre à analogia libidinal para descrever cada uma das dimensões segundo categorias de prazer. À primeira ele dá o nome de prazer da geometria, o prazer da ordem ou dos conceitos, que concebe a arquitetura como uma "coisa mental" e que desencadearia uma "poética de signos congelados [...] voltados para um prazer mental, gélido." Já aquela que se refere ao labirinto, o prazer do espaço, desencadearia uma relação entre as formas dos espaços com as formas do corpo, acentuaria "as propriedades espaciais do [...] corpo", "uma forma de experiência - a 'presença da ausência'." (TSCHUMI, 2006a, p. 576).

Tschumi sugere que os valores elevados do espírito não são mais do que uma satisfação sensual pela ordem e que esta intenção pode ser tão (i)legítima quanto qualquer extravagância 
aparentemente irracional, não menos paranoica em sua obsessão pela lisura. Ele conclui que nem um nem outro são, sozinhos, o prazer da arquitetura e reconhece o arquiteto tanto como criador de experiências quanto manipulador da técnica. O prazer mental estaria então dotado de um valor em si capaz de subjugar a experiência. Esta última, por sua vez, carece de formas de representação capazes de exprimi-la e, portanto, atribuir-lhe valor.

A partir deste ponto, o arquiteto sugere uma redefinição do escopo teórico da disciplina. Por ser a arquitetura uma atividade que estabelece fronteiras, seriam justamente as obras que desafiam os limites da disciplina aquelas mais aptas para redefinir sua natureza.

Colocá-las em questão não é simplesmente exaltar o que essas estratégias rejeitam. Ao contrário, significa entender o que as atividades de fronteira escondem e encobrem. Esse tipo de história e de reflexão crítica e analítica ainda está por ser realizada. Não como um fato marginal (de poetas, visionários ou, pior, de intelectuais), mas como um fenômeno crucial para a natureza da arquitetura. (TSCHUMI, 2006b, p. 176)

Obras arquitetônicas que reivindicam uma condição de arte e artistas que manipulam o espaço construído seriam dois lados dessa fronteira da mesma forma que nas cidades a fronteira é tensionada pelo que não se aceita para além de mera construção, sejam favelas ou condomínios de luxo. Do lado de fora da fronteira está aquilo que foi negado como prática legítima da arquitetura, mas no lado de dentro também estão práticas arquitetônicas limitadas pela fronteira.

A tríade vitruviana estabelece um fundamento basilar para a disciplina e Tschumi procura demonstrar de que maneira estes conceitos precisam ser expandidos para que a arquitetura avance em direção a novos paradigmas e ainda se mantenha coesa.

O único juiz competente sobre o último termo da trilogia [utilitas], acomodação espacial adequada", é, naturalmente, o corpo, o seu corpo, o meu corpo - o ponto de partida e o ponto de chegada da arquitetura. A concepção cartesiana do corpo-como-objeto foi contraposta pela visão fenomenológica do corpo-como-sujeito e a materialidade e a lógica do corpo se opuseram à materialidade e à lógica dos espaços. Do espaço do corpo para o corpo-no-espaço - a passagem é intricada. [...]. A arquitetura ainda não começou a analisar as descobertas vienenses da virada do século, se é que algum dia a arquitetura virá a informar a psicanálise mais do que esta informou a arquitetura. [...] Os corpos não somente se movem para o seu interior, mas produzem espaços por meio e através de seus movimentos. (TSCHUMI, 2006c, p. 180-181)

A sugestão de eleger o corpo sensível como critério da acomodação adequada se opõe a noção inevitável da funcionalidade em função da eficiência, do controle e da ordem serial que o paradigma mecânico impõe ao corpo. Da mesma forma serve de critério para a produção na medida em que explicita a relação de sujeitos trabalhadores com a construção.

Nem o modernismo, nem o pós-modernismo teriam estabelecido relações entre os edifícios e os corpos agenciados por eles no sentido de transpor a noção de objeto-indivíduo para uma noção mais ampla enquanto processo-sujeito, desde a sua construção até sua relação com o território e o tempo.

A não ser pelos meios estéticos diversos, ambas concebem a arquitetura como um objeto de contemplação, facilmente acessível à percepção crítica, ao contrário da 
interação do espaço com os eventos, que normalmente não é objeto de comentários. (TSCHUMI, 2006c, p. 187)

Antagonismos semelhante foram desenvolvidos pela teoria feminista a partir das concepções morais que distinguem e hierarquizam os gêneros e exercem controle de conduta pela sexualidade.

Diana Agreste sugere uma revisão historiográfica a partir do renascimento, quando teria sido delimitado o sistema arquitetônico ocidental (AGREST, 2006, p. 586) que desde sua origem internalizou uma sistemática exclusão da mulher e repressão de seu corpo ao mesmo tempo em que elaborou um sistema de regras sintáticas, elementos e significados arquitetônicos a partir do corpo masculino.

A lógica do sistema de arquitetura reprime o sexo de duas maneiras diferentes: entendendo-o e em termos positivos e negativos e atribuindo à mulher o termo negativo (falocentrismo). Além disso, o sexo é neutralizado ou eliminado com o meio usado pelo artista, o qual, assexuado, gera de modo autônomo e dá a luz uma obra, o produto da criação. (AGREST, 2006, p. 586)

O pressuposto é o edifício como metáfora do corpo. Para os arquitetos do Renascimento o projeto tem como meta uma objetividade delimitada em que as dimensões de um todo deverão estar em função de partes e membros (AGREST, 2006, p. 589). Desta forma, o edifício é entendido pelo arquiteto como uma completude apreendida em sua totalidade acabada, com limites definidos. Um sistema abstrato completo e fechado.

A metáfora vai mais a fundo quando pressupõe que o edifício é passível de nascimento e morte. Neste ponto, o arquiteto ocupa o corpo da mãe, a figura genuinamente feminina, e a gestação se equipara ao projeto. De maneira demiúrgica, cria o novo a partir de um gesto autônomo assistido por uma figura paterna ambígua, o patrono ou o próprio arquiteto. 0 corpo da mulher surge apenas para ser representado pelo homem. Ao contrário da gestação, que é inevitavelmente processo de criação com o outro, o arquiteto reivindica para si o monopólio da autoria ainda que submetido à figura do patrono.

O ideário cristão atravessa o repertório Renascentista e o projeto arquitetônico é elevado à dimensão da concepção imaculada na forma de um ato de vontade puro e assexuado, ou seja, com o destino traçado por uma autoria (autoridade). Mais do que uma simples alusão ao contexto religioso, as metáforas renascentistas interiorizam os dogmas morais da igreja católica e oculta-os sob a ideologia racional oportuna para a diferenciação de um Renascimento lógico em oposição a uma Idade Média mística.

O ponto de vista da mulher que olha a partir de fora destes limites passa a ser um ponto de vista privilegiado segundo a autora. O modernismo se revela como uma continuidade destes mecanismos. Assim como o Renascimento teria coberto o paradigma cristão sobre o manto da tradição clássica, a modernidade parece ter suposto que a máquina neutralizaria estes efeitos em vez de reproduzi-los. A própria noção de máquina parece mais resultado desse processo do que ruptura com ele. As vanguardas modernas se estabelecem no lugar de antigas instituições reivindicando para si a continuidade do legado cultural. Nestes momentos de transformação são 
reestabelecidas as fronteiras entre o que se pretende incluir e o que se pretende negar. $A$ contribuição feminista de Agrest, no entanto, chama a atenção para o fato de que a arquitetura se define inevitavelmente por ambas as partes.

\section{De dentro para fora}

Não necessariamente a inclusão do que foi marginalizado completa os fatos, mas a maneira como se dá o corte é mais eficientes para esclarecer o que se manifesta e o que se nega.

Os interiores domésticos são mistérios capazes de esconder mecanismos ocultos de controle intrínsecos ao sistema arquitetônico. O interior, paradoxalmente, talvez seja o lugar mais distante e marginalizado pela arquitetura. Uma metáfora conveniente do inconsciente como espaço misterioso e revelador.

Traços do cotidiano - ou seja, espaço como acumulação de gestos no tempo - são evidências de um agenciamento entre as formas arquitetônicas e os corpos. Através deles podemos desenvolver uma tradução historiográfica da experiência do espaço arquitetônico a partir de uma sistematização que reúne aspectos psicológicos com intenções de projeto.

Uma variedade de fontes articuladas pode compor a historiografia da arquitetura e da cidade. Se por um lado declarações e textos nos revelam intenções dos arquitetos ou modos de atribuir função e sentido para elementos da arquitetura, por outro as imagens e representações do espaço demonstram estas intenções operando sobre o corpo e sobre o imaginário. Paredes e aberturas escondem e direcionam o olhar que incide no corpo na forma de um estímulo psicológico que vai além do fascínio contemplativo. Proteção e insegurança, proximidade e distanciamento, agorafobia e claustrofobia, voyeurismo e exibicionismo.

Assim como Tschumi reivindica para o projeto, Colomina sugere para o registro historiográfico uma apreensão dos espaços arquitetônicos como experiências complexas ${ }^{1}$. Também recorre à analogia libidinal para descrever o espaço através de dispositivos psicológicos do olhar, do controle e dos regimes do olhar que delimitam a fronteira entre interior e exterior, do que pode ser visto e do que não pode ser visto e o modo através do qual esse olhar é fonte de controle. A analogia libidinal parece esclarecer que os estímulos psicológicos do espaço, seus atributos formais e conceitos incidem simultaneamente no corpo, menos como adições e mais como justaposição e sobreposição.

Colomina refere-se à reciprocidade deste olhar, o qual atribuiu a essa dimensão espacial, a partir de Lacan e sugere que "a arquitetura não seria simplesmente uma plataforma que acomoda sujeitos que observam. Ela é um mecanismo de observação que produz o sujeito.

$1 \quad$ O texto The Split Wall: Domestic Voyeurism, além de fazer parte do livro Privacy and Publicity: Modern Architecture as Mass Media de 1994 já estava na coletânea Sexuality and Space organizada também por Colomina e publicada em 1992. Joan Ockman publica Architecture Culture em 1993 e Diana Agrest publica The Sex of Architecture em 1996 ambos com o formato semelhante. 
Ela precede e enquadra o ocupante."(COLOMINA, 1992, p.83)².Portanto, uma espécie de alteridade.

Este argumento servirá de fundamento para paralelos entre as casas projetadas por arquitetos da vanguarda modernista e os paradigmas da representação na cultura. $O$ teatro, no caso de Adolf Loos, o cinema e a fotografia, no caso de Le Corbusier. Paradigma presencial no caso do teatro e virtual no caso do cinema. Estes modos de ver são constantemente citados pelos arquitetos e Colomina procura descrever as implicações no espaço.

Em Loos, cada uma de suas casas estabelece uma relação cênica entre espaços (palco, plateia, boca de cena) e observadores. Como no teatro, o limite entre ator e espectador está delimitado entre os cômodos e o olhar se volta para o interior assim como a luz que entra pelas janelas. " ${ }^{3}$ A casa é o palco para o teatro da família, o lugar onde as pessoas nascem, vivem e morrem." (COLOMINA, 1992, p.85, tradução nossa) ${ }^{4}$. O espaço dá forma a estas instituições sociais e elas atribuem sentido aos espaços.

A autora demonstra o modo como Loos entende a arquitetura como uma forma de coberta ao estabelecer um sentido entre peças do vestuário e o espaço construído que envolve o corpo. O abrigo protege e causa satisfação, mas está tão separado do corpo que exige uma estrutura própria. A roupa, tanto quanto o espaço, dissimulam o corpo e estabelecem uma representação cênica. Espaço como palco; roupa como máscara.

O interior doméstico abriga a intimidade e se distingue em função do exterior metropolitano. "A tensão entre a sensação de conforto e o conforto como controle interfere no papel da casa como forma tradicional de representação". (COLOMINA, 1992. p. 92, tradução nossa $)^{5} \mathrm{O}$ exterior masculino e o interior feminino são construídos mutuamente a partir dessa diferença entre o que deve ser comum a todos e as diferenças que permanecem confinadas na intimidade. A fachada e o lado de dentro da casa se diferenciam como espaços e se definem como interiores e exteriores a partir de um imaginário simbólico - da mesma forma que o corpo e as identidades de gênero.

A casa projetada por Loos para a dançarina Josephine Baker é apresentada como paradoxo entre estas noções. No corredor perimetral da casa, o ocupante tem, de um lado, as janelas voltadas para fora; do outro, janelas voltadas para o interior da piscina, dentro da casa. A condição deste ocupante serve como exemplo da condição do próprio arquiteto e da crítica em relação aos objetos arquitetônicos. Eles, assim como o ocupante, não estariam nem dentro nem fora da obra. Assim como o arquiteto cria objetos e atribui sentidos a eles, a crítica impregna

2 Tradução livre do original em inglês: "Architecture is not simply a plataform that accommodates the viewing. It is a viewing mechanism that produces the subject. It precedes and frames its occupants.

3 Beatriz Colomina menciona uma pPassagem do livro Urbanisme de Le Corbusier(1925) em que ele se refere ao arquiteto austríaco: "Loos told me one day: A cultivated man does not look out of the window; his window is a ground glass; it is there only to let the light in, not to let the gaze pass through." (CORBUSIER, 1925, p.174 apud COLOMINA, 1992. p.74)

$4 \quad$ Tradução livre do original em inglês: "The house is the stage for the theater of the family, a place where people are born and live and die."

5 Tradução libre do original em inglês: The tension between sensation of comfort and comfort as consttrol disrupts the role of the house as a tradicional form of representation. 
estes objetos arquitetônicos. "Incapaz de se separar do objeto, o crítico simultaneamente produz um novo objeto e é produzido a partir dele." (COLOMINA, 1992, p. 96, tradução nossa) ${ }^{6}$ Registros, descrições, fotografias e interpretações são fragmentos que se instalam na obra a partir de intermediários que proliferam objetos diferentes. Ao reproduzir estes encadeamentos, a historiografia apresenta novas versões deste objeto e se constitui a partir deles.

Já em Le Corbusier, as casas são descritas praticamente como opostos das casas de Loos. O olhar se volta constantemente para fora e captura uma paisagem enquadrada pela arquitetura. Trazem para dentro a imagem, mas afastam aquele ambiente do corpo do espectador. Sensualidade e erotismo se confundem. O espaço não necessariamente possui os mesmos atributos que as imagens projetadas. $O$ interior é definido por esse exterior planificado nas superfícies de vidro. O ocupante é necessariamente um voyeur.

Como vimos, o olhar voyeur não só captura a imagem para si, embora seja sua condição ideal, mas recebe de volta o olhar do outro, mesmo que este seja o espaço. Em fotografias e vídeos da Vila Savoye, percorre-se a casa como esse voyeur, mas as regras não são as mesmas para diferentes observadores. As mulheres nunca olham diretamente para câmera, também não estão necessariamente olhando a paisagem para além da casa. É evidente que elas não podem devolver o olhar ao voyeur.

Vista sempre no interior, a mulher tem uma posição fixa no regime da imagem. Ao comparar as casas de Le Corbusier com a mídia de massa, através do cinema e da fotografia, podemos perceber esse paralelo em que ambas pressupõem olhares de uma direção e não de dupla direção como no teatro, por exemplo. A reciprocidade dos olhares, da construção mutua e simultânea da presença, dá lugar a uma profusão de imagens em uma direção. Ela pode tanto revelar quanto esconder, a diferença é que o dispositivo antecipa o enquadramento e consegue de antemão editar o olhar.

\section{De fora para dentro.}

O olhar minucioso a partir da experiência revela contradições e esclarece conceitos perdidos em favor de uma coesão ideológica ou estilística. A parte, vista de outra forma, faz o todo diferente.

A cidade não é um todo sintético como um projeto arquitetônico, é encadeamento justaposição, sobreposição, imposição - de espaços construídos, direta ou indiretamente projetados. Os arquitetos não foram e nem serão autores de todos estes projetos e, mesmo assim, uma amostra de espaços construídos nos revelaria muito em comum e muito de particular em cada fragmento da cidade.

Se o ambiente doméstico pode revelar aspectos a partir da reação ao espaço urbano metropolitano, a própria cidade se conforma a partir do embate entre grandes políticas, planos e projetos com as pequenas e constantes transformações no cotidiano.

$6 \quad$ Tradução livre do original em inglês: "Incapable of detachment from the object, the critic simultaneously produces a new object an is produced by it." 
Joan Ockman (2004) descreve os anos do pós-guerra em Nova York a partir de duas imagens da arquitetura na cidade. A primeira é o arranha-céu Lever House, que ela define tanto como ícone do Estilo internacional quanto como "face pública do capitalismo corporativo americano."(OCKMAN, 2004 p. 342, tradução nossa) ${ }^{7}$. A segunda, o conjunto Levittown, foi um bairro inteiramente construído de habitações isoladas em lotes no subúrbio, característicos nos Estados Unidos e que traduzem o "imaginário da vida privada socialmente tradicional e esteticamente conservadora" (OCKMAN, 2004, p. 342, tradução nossa) ${ }^{8}$.

Configura-se, em resumo, que a dicotomia predominante entre Lever House e Levittown contempla alta eficiência, intenso senso prático, e arranjo social simbiótico. Em uma sociedade que buscou promover simultaneamente a máxima produtividade e o máximo consumo, as esferas público e privada tiveram papéis distintos, mas complementares. A arquitetura serviu para reproduzir e reforçar essa divisão social de gênero, promovendo imagens eficientes para cada um deles.

$\mathrm{Na}$ atualidade, é claro, estas duas formas de representação foram reflexos de um único sistema, dois lados da moeda do capitalismo. Ambos [...] foram baseados em processos de produção altamente racionalizados e otimizados; ambos foram orientados por uma sociedade de massa do pós-guerra. Eles se diferem nas imagens que projetam, por um lado na elite da estética modernista, por outro, no gosto cultural médio" (OCKMAN, 2004 , p. 348, tradução nossa) $)^{9}$

Eles demarcam estes dois extremos da produção e do consumo e, ao longo do texto, a autora costura uma trama entre eles. De um lado, as intenções, motivações e necessidades políticas e econômicas e, do outro, os aspectos da vida cotidiana do trabalho e dos afazeres do lar. A separação radical acentua uma divisão de gênero que caracteriza o espaço naquele momento.

Uma classe média com privilégios em massa conforma novos estereótipos. De um lado, o executivo, homem de negócios, substitui o operário como protótipo do trabalhador no imaginário do Estilo Internacional. Por outro, a dona de casa moderna aparece como estereótipo ideal para as mulheres que perderam seus postos de trabalho conquistados durante a guerra e voltaram para o trabalho doméstico e o consumo em seus lares.

O período do fim da guerra é reconhecido como um momento em que a indústria americana substitui a absorção de capital da indústria bélica, com o intuito de manter o crescimento, para outros setores da economia. Os dois exemplos são partes que se completam nesse processo. A união da modernidade capitalista com o estilo internacional demonstra a

7 Tradução livre do original em inglês: “...an early icon of International Style modernism, public face of American corporate capitalism.

8 Tradução livre do original em inglês: “...embodiment of suburban single-family domesticity, a visiono of private life socially tradicional and aesthetically conservative.

${ }_{9} \quad$ Tradução livre do original em inglês: It would seem, in short, that the prevailing dichotomy between Lever House and Levittown amounted to highly efficient, eminently practical, and symbiotic social arrangement. In a society that sought simultaneously to promote maximum productivity and maximum consumption, the public and private spheres had separate but complementary roles to play. Architecture served to reproduce and reinforce this gendered social division, providing an efficacious image for each.

In actuality, of course, the two forms of representation were mirror images of a single system, two sides of the capitalist coin. Both [...] were predicated on highly rationalized and optimized production processes; both were geared to a postwar mass society. Where they differed was in the image they projected, in the one case of elite modernist aesthetics, in the other of mid cult taste.

(c) Urbana: Rev. Eletrônica Cent. Interdiscip. Estud. Cid. $\quad$ Campinas (SP) $\quad$ v.7, n.2 [11] $\quad$ p.86-96 $\quad$ ISSN 1982-0569 
posição de prestígio que essa imagem adquiriu e a ascensão de uma nova economia empresarial. Os subúrbios dão início a uma indústria cujo produto principal é a própria cidade, que pode ser construída em série, que concentra produção e riqueza, viabiliza alta capacidade de lucro e especulação financeira, além de mobilizar outros grandes setores da economia, como os produtos domésticos, mobiliário, automobilístico e de combustível.

Embora estejam comprometidas com os mesmos processos econômicos, as imagens das esferas pública e do trabalho se distinguem da esfera doméstica. A mídia de massa através da publicidade - e vice-versa - contribui, a partir deste momento, com a manipulação elástica destas imagens. O Estilo Internacional, reconhecido como estética da alta cultura modernista nos Estados Unidos neste momento, "incorpora os valores da tecnocracia - o ethos do racionalismo, burocracia e do progresso técnico científico nos quais grandes negócios e o governo se baseavam. "(OCKMAN, 2004, p.348, tradução nossa) ${ }^{10}$ Os arranha céus envidraçados se estabelecem como face pública monumental metropolitana no lugar da noção monumental cívica. Ao mesmo tempo, as casas são fabricadas em série com aspectos conservadores nos subúrbios, a partir de um gosto médio de prestígio tradicional.

A autora evoca uma distinção de gênero entre estes dois novos protótipos de espaço urbano, mas não dá muita atenção para outros paradoxos. Ockman chama a atenção para o fato de que ni interior dos escritórios, quanto mais alto o cargo dos executivos, mais conservador se torna o aspecto do ambiente, enquanto secretárias e baixos funcionários trabalham em ambientes sóbrios e acéticos projetados para a máxima eficiência funcional. Não faz menção, no entanto, aos conjuntos habitacionais, como o desastroso Pruitt-Igoe, que neutraliza qualquer diferenciação em nome da eficiência funcional.

O cruzamento destas grandes políticas e da sedução das imagens propõe uma relação entre a ideologia arquitetônica e a modernidade capitalista. Nem uma história do urbanismo, nem uma história da cidade, mas uma historiografia da arquitetura na cidade. A cidade não como resultado ou antítese da arquitetura, mas como fenômeno em si em que as expressões da técnica, da economia, da cultura e da política são vetores que incidem em um território comum e estabelecem um resultado combinado. Os edifícios têm a capacidade de sintetizar estes fenômenos, participam deste conjunto e o define ao mesmo tempo em que são transformados por ele.

Se o período descrito acentua ao máximo as concepções urbanas de acordo com divisões de gênero, é justamente neste momento que eles começam a se transformar. Suprir demandas de mercado passa a ser tão relevante quanto criar demandas a partir da publicidade, da diferenciação dos produtos e de estereótipos de identidade. Se antes as mulheres eram alvo prioritário da publicitária como consumidoras e os homens tinha posição privilegiada na produção, agora eles também estão sujeitos a ordem do consumo a qual são incapazes de manipular e que ameaça a própria hegemonia do controle pela produção.

10 Tradução livre do original em inglês: "incorporate the values of technocracy - the rationalism ethos, bureaucracy and scientific technical progress in which corporations and government were based. 
A pós-modernidade, na avaliação da autora, supera até certo ponto diferenças entre os gêneros na medida em que as mulheres vão ocupando o novo contexto consumista nas mesmas condições que os homens. Na arquitetura, a ilusão de imagem neutra da racionalização dá lugar a uma miríade de diferenciações. Neste contexto, elas são uteis tanto para dissolver estereótipos femininos e masculinos quanto para fabricar demandas e promover o consumo.

A autora entende as mudanças como positivas para o feminismo, mas, ao demonstrar claramente sua posição, podemos supor que o paradigma é favorável na medida em que encurrala ambas as partes contra o mesmo desafio de lidar com o consumismo. Entretanto, considerando o que sugere sua historiografia, não se pode considerar positivas ou não as transformações das imagens em relação ao sistema como um todo. A produção não se modifica na mesma medida em que se modificam as imagens das mercadorias. As imagens já não são representações fiéis da produção, mas poderosas ferramentas de controle. O desafio é procurar entender qual papel cada uma, imagem e produção, exerce em relação a outra e vice-versa.

A leitura historiográfica favorece vantagens para a compreensão destes papéis na medida em que reconstitui a sucessão de episódios cotidianos ao mesmo tempo em que avalia as narrativas lineares. São dois aspectos de tempo na cidade, assim como aqueles aspectos do espaço. O tempo constante e durável, linear, cumulativo e excepcional da ordem pública e das instituições, e outro, descontínuo, do cotidiano, da repetição e da diferença, que são cíclicas.

A ilusão de linearidade é comum às instituições, e a história das instituições se confunde com a história vivida. Subestima-se o tempo descontínuo das gerações que precisam transmitir os valores institucionais para que a ilusão de progresso exista.

\section{Referências}

AGREST, Diana. À margem da arquitetura: corpo, lógica e sexo. In: NESBITT, K. (org.) Uma nova agenda para a Arquitetura. Antologia Teórica 1965-1995. São Paulo. Cosac Naify, p. 584599 , <Publicado originalmente em Assemblage, n. 7, pp. 29-41, 1988.>

COLOMINA, Beatriz. Split Wall: Domestic Voyeurism. In: COLOMINA, B.(org.) Sexuality and Space. Nova York. Princeton Architectural Press, 1992.

LEFEBVRE, Henri. Toward an Architecture of Enjoyment (edited by Łukasz Stanek; translated by Robert Bononno), Minneapolis: University of Minnesota Press, 2014.

NESBITT, K.(org.). Uma nova agenda para a Arquitetura. Antologia Teórica 1965-1995. São Paulo. Cosac Naify, p. 584-599, 2006.

OCKMAN. Joan. Mirror images: technology, consumption, and representation of gender in Americna architecture since World War II. In: Eggener, K. (org). American Architectural History. Nova York: Routledge, 2004.

TSCHUMI, Bernard. "Arquitetura e Limite I In: NESBITT, K. (org.) Uma nova agenda para a Arquitetura. Antologia Teórica 1965-1995. São Paulo. Cosac Naify, p.172-177. 2006 <Publicado originalmente em Artforum 16, n. 4, p.36, dez.1980. >

TSCHUMI, Bernard. "Arquitetura e Limite II. In: NESBITT, K. (org.) Uma nova agenda para a Arquitetura. Antologia Teórica 1965-1995. São Paulo. Cosac Naify, p.177-182, 2006. <Publicado originalmente em Artforum 19, n. 7, p. 45, mar. 1981. >

TSCHUMI, Bernard. "Arquitetura e Limite III. In: NESBITT, K. (org.) Uma nova agenda para a Arquitetura. Antologia Teórica 1965-1995. São Paulo. Cosac Naify, p. 183-188, 2006. 
<Publicado originalmente em Artforum 20, n. 1, p. 40, set. 1981.>

TSCHUMI, Bernard. O Prazer da Arquitetura In: NESBITT, K. (org.) Uma nova agenda para a Arquitetura. Antologia Teórica 1965-1995. São Paulo. Cosac Naify, p. 573-584, 2006. <Publicado originalmente em Architectural Design 47, n.3, p. 214-218,1977>

TSCHUMI, Bernard. Architecture and Disjunction (1975-1990). Cambridge. MIT Press. 1996

TSCHUMI, Bernard. O Prazer da Arquitetura In: NESBITT, K. (org.) Uma nova agenda para a Arquitetura. Antologia Teórica 1965-1995. São Paulo. Cosac Naify, p. 573-584, 2006. <Publicado originalmente em Architectural Design 47, n.3, p. 214-218,1977> 